\title{
The Genetic Control of the $\alpha$-Amylase Isozymes of the Durum Wheat (Triticum durum Desf.)
}

\author{
D. O. Prokopyk, M. Z. Antonyuk, and T. K. Ternovskaya \\ The National University “Kyiv-Mohyla Academy,” Ukraine
}

\begin{abstract}
The hybridoiogical analysis was provided on several durum wheat genotypes with utilizing three $\mathrm{F}_{2}$ populations developed from the crossing between parental forms that differed in the invariable malt-zone triplet on elecirophoretic spectrum of $\alpha$-amylase. Three components of this zone are controlled by three genes with an independent way of inheritance: one of them is located on the $6 \mathrm{~B}$ or $5 \mathrm{~B}$ chromosome, and two genes are located on the chromosomes of A subgenome.
\end{abstract}

\section{INTRODUCTION}

The cereal $\alpha$-amylase genes are divided into two large classes- $A m y A$ and $A m y B$ [1]. The $A m y A$ class, in its turn, is divided into two subfamilies, Amyl and Amy2 [2l. The $A m y B$ class contains the Amy 3 subfamily $[1,3] . \alpha-A m y-1$ genes are expressed in seed under the induction of gibberellic acid, which is produced by embryo [4], are located on the chromosomes 6A, 6B, and $6 \mathrm{D}$, and encode a "malt" type of $\alpha$-amylases that are expressed at the initial stages of seed germination (the $1-4^{\text {th }}$ days). $\alpha-A m y-2$ genes are located on $7 \mathrm{~A}, 7 \mathrm{~B}$, and 7D chromosomes [5-8]. Expression of these genes takes place on the later stages of germination (the $4-7^{\text {th }}$ days), and their products are regarded as a "green" type of amylases. $\alpha-A m y-3$ genes are expressed on the low level during the embryo formation [2], but at the high one in the aleurone layer during the germination $[9,10]$. Amylase genes are multiple: we could distinguish nearly $12-14 \alpha$-Amy- 1 genes and $10-12 \alpha$-Amy-2 ones $[1,11]$. The difference between these isozymes was revealed by means of isoelectric focusing $[7,8] . \alpha-$ Amy-3 genes are mapped on the chromosomes of the $5^{\text {th }}$ homeologous group $[2,12]$. Both gene groups are polymorphic and usually vary among different varieties and landraces $[8,13,14]$. Nevertheless, this polymorphism is discovered first of all by isoelectric focusing [7, 8, 14], and native electrophoresis of amylase shows significantly less polymorphic spectra $[5,6,15,16]$.

Malt zone of common wheat (Triticum aestivum L.) $\alpha$-amylase electrophoretic spectrum in non-denaturing PAAG usually consists of six components. It was shown, that the first, second, and the third components (in the direction of their mobility enhancement) are controlled by genes located on 6D, 6B, and 6A chromosomes respectively $[5,6]$. Genetic control of the next three bands of malt-zone spectrum part is yet undeter- mined. The utilization of nulli-tetrasomics for the $6^{\text {th }}$ and the $7^{\text {th }}$ homeologous groups failed to dissect this triplet, as all the bands were always present on the spectrum $[6,16]$.

Previous investigations concerning genetic control of $\alpha$-amylase spectrum components were conducted on hexaploid and some tetraploid $\mathrm{A}^{\mathrm{b}} \mathrm{A}^{\mathrm{b}} \mathrm{BB}$ wheat genotypes, and demonstrated a considerable isozyme polymorphism [7, 8, 13, 14]. But in these works the separation of isozymes was conducted by means of isoelectric focusing in the thin-layer PAAG, which is known for its labor- and resource-intensivity, and, therefore, does not suit for genetic analysis. Moreover, this method, despite its high resolution ability, did not shed light on the question about genetic control of invariable maltzone bands. In previous works native electrophoresis did not reveal any polymorphism in this zone among common wheat genotypes $[7,8,15,16]$.

The question about localization of genes that control permanent bands of the malt-zone is quite important while these genes are suitable and efficient chromosome-specific markers, which demonstrate moderate polymorphism among common and durum wheat genotypes. This paper expounds the results of the investigation, the objective of which was to ascertain the genetic control of durum wheat $\alpha$-amylase isozymes that form the invariable malt-zone triplet.

\section{MATERIALS AND METHODS}

The genetic stocks used in this research were forms and cultivars with the genomic formula $\mathrm{AABB}, 2 n=$ 28 , namely durum winter wheat cultivar Chornomor (developer-O.I. Palamarchuk, Odessa), durum winter lines Leucurum, Rubrum, and Candicance, kindly provided by Plant Groving Institute after Jurjiv V.Ja., (Kharkiv), winter durum wheat line Mutiko italikum $59 \mathrm{~h} 132$, developed and kindly provided by breeder 


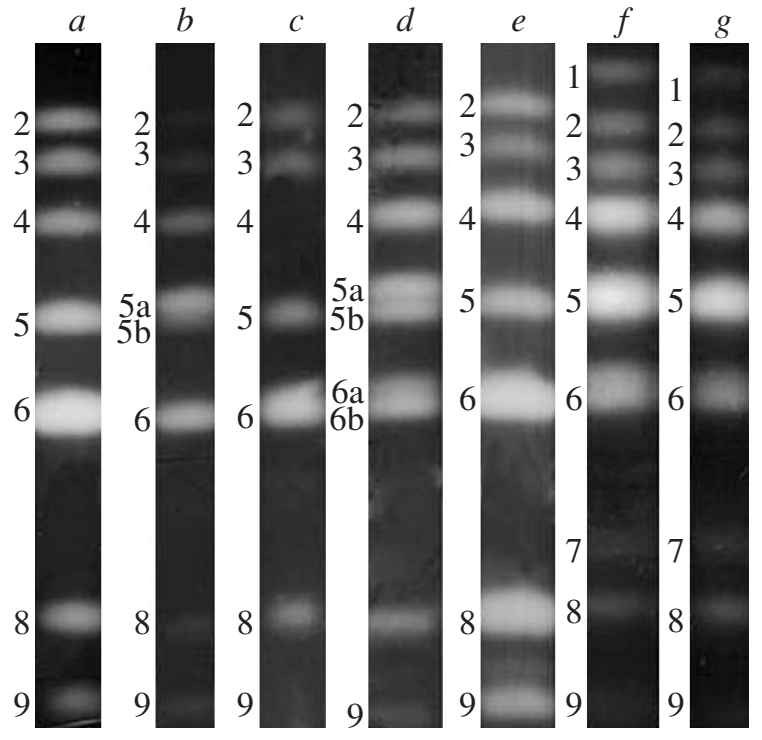

Fig. 1. The electrophoretic spectra of some dumm and common wheat genotypes: $a-$ Rubrum, $b$-Chornomor, $c$-Leucurum, $d$-Mutiko italicum, $e$-Candicance, $f$-Avrora, $g$-Kavkaz.

V.V. Kostin, KNIAC, Krasnodar. The mentioned parental forms were crossed after the diallelic scheme without reciprocal crossings. The $\mathrm{F}_{1}$ plants were allowed to self-pollinate under the isolators. The $\mathrm{F}_{2}$ individuals were grown, and seeds obtained from each plant were used in this investigation for $\alpha$-amylase extraction.

For $\alpha$-amylase spectra obtainment the following stocks were also used: common wheat cultivars Chinese Spring, Kavkaz, Avrora (the genomic formula AABBDD), and species T. boeoticum Boiss. $\left(\mathrm{A}^{\mathrm{b}} \mathrm{A}^{\mathrm{b}}\right)$, T. timopheevii Zhuk. ( $\left.\mathrm{A}^{\mathrm{b}} \mathrm{A}^{\mathrm{b}} \mathrm{GG}\right)$, and nulli-tetrasomics for $6^{\text {th }}$ and $7^{\text {th }}$ homologous groups, developed from Chinese Spring cultivar, in all possible combinations.

The extraction buffer for $\alpha$-amylase contained sucrose $30 \%$, calcium chloride $0.2 \%$, bromphenolic blue stain. The PAAG for $\alpha$-amylase was non-denaturing, had a thickness $6.5 \%$, contained $0.02 \mathrm{M}$ tris, $0.06 \mathrm{M}$ glycine, and $5 \mathrm{M}$ carbamide; the ratio between acrilamide and bisacriiamide was $1: 30$. The electrode buffer has $\mathrm{pH} 8.4$, and contained $0.01 \mathrm{M}$ tris and $0.06 \mathrm{M}$ glycine. The $\alpha$-amylase pre-stain contained $12 \mathrm{~g}$ of hydrolysed starch, $134 \mathrm{ml} 0.1 \mathrm{M}$ acetic acid, and $3.6 \mathrm{~g}$ of sodium acetate on the basis of $400 \mathrm{ml}$ of solution. The Lugol solution for the gel staining contains $0.03 \mathrm{M}$ potassium iodide, $0.01 \mathrm{M}$ iodine, $8.4 \%$ trichloroacetic acid. The $\alpha$-amylase isozymes were extracted from the germinated seeds with coleoptiles $0.5-3 \mathrm{~cm}$ long. The germinated seeds were crashed in $1 \mathrm{ml}$ of extraction buffer and incubated during $6-18 \mathrm{~h}$ at $4^{\circ} \mathrm{C}$. Before drifting on the gel the samples were centrifuged for $3 \mathrm{~min}$ under the acceleration $8000 g$; on each cell $5 \mu \mathrm{l}$ of extract were drifted [16]. The $\alpha$-amylase separation was performed from cathode to anode under the voltage
$300 \mathrm{~V}$ and the current strength $0.4-1 \mathrm{~mA}$ for each centimetre of gel. After the run gels were incubated in the $3 \%$ starch solution during 40-60 min, washed a little and stained with Lugol solution.

\section{RESULTS AND DISCUSSION}

On the elecrtophoretic spectra of $\alpha$-amylase derived from common and durum wheat genotypes (Fig. 1) components 1-6 correspond to malt zone, and 7-9- to the green one [7, 8, 16]. Band 1 is controlled by AmyD1 gene, located on 6D chromosome [7, 16]. This explains why the spectrum of durum wheat lacks it. Bands 2 and 3 are the products of $\alpha-A m y-1$ genes, which are located on the chromosomes $6 \mathrm{~B}$ and $6 \mathrm{~A}$ respectively $[7,16]$. Components 4,5 , and 6 form so named invariable malt-zone triplet, and the genetic control of the respective isozymes is yet undetermined. Bands 7, 8, and 9 of common wheat and 8, 9 of durum wheat are the products of $\alpha-A m y-2$ genes, which are located on the chromosomes of the $7^{\text {th }}$ homeologous group 7D, 7A, and 7B and 7A, 7B respectively [7, 16].

The polymorphism in the invariable triplet was observed among five durum wheat genotypes (Figs. 1a-1e). The spectrum of Leucurum lacks band 4 (Fig. 1c), and demonstrates single bands 5 and 6 , whereas the spectrum of MI (Fig. 1d) has band 4, and shows double bands 5 and 6 . They are numerated as $5 \mathrm{a}$, $5 \mathrm{~b}$, and $6 \mathrm{a}, 6 \mathrm{~b}$. The invariable triplet spectra of Rubrum and Candicance have all three components (Figs. 1a, 1e), and Chornomor's spectrum (Fig. 1b) has bands 4, 6, and double 5 . The availability of the polymorphism in the malt-zone triplet among some durum wheat representatives provides a possibility of using these genetic stocks in the genetic analysis of the triplet's components genetic control.

The electrophoretic spectra of different nulli-tetrasomics for the $6^{\text {th }}$ homeologuos group approve previous results and provide evidence that whichever chromosome was absent, none of the triplet's bands disappeared. So, we may conclude, first of all, that isozymes, which genes locate on different chromosomes, may have the same electrophoretic mobility and therefore collide on the spectrum. To check this assumption, we examined the spectra of the diploid wheat $T$. boeoticum Boiss. $\left(\mathrm{A}^{\mathrm{b}} \mathrm{A}^{\mathrm{b}}\right.$ genome $)$ and tetraploid wheat $T$. timopheevi Zhuk. ( $\mathrm{A}^{\mathrm{b}} \mathrm{A}^{\mathrm{b}} \mathrm{GG}$ genome).

The spectrum of diploid species T. boeoticum is presented only by two bands, which are both located in the invariable triplet zone. These bands are the $5^{\text {th }}$ and the $6^{\text {th }}$, and the latter could vary among different einkorn samples and be either single or double (Figs. 2a, 2b). Such a spectrum could appear in two cases: when AmyAl gene is a cluster and its different alleles could provide two or three electrophoretic bands, or when the genome of einkorn has two distinct genes, which products form the invariable malt-zone triplet. The latter case also provides two alternatives, when both genes 


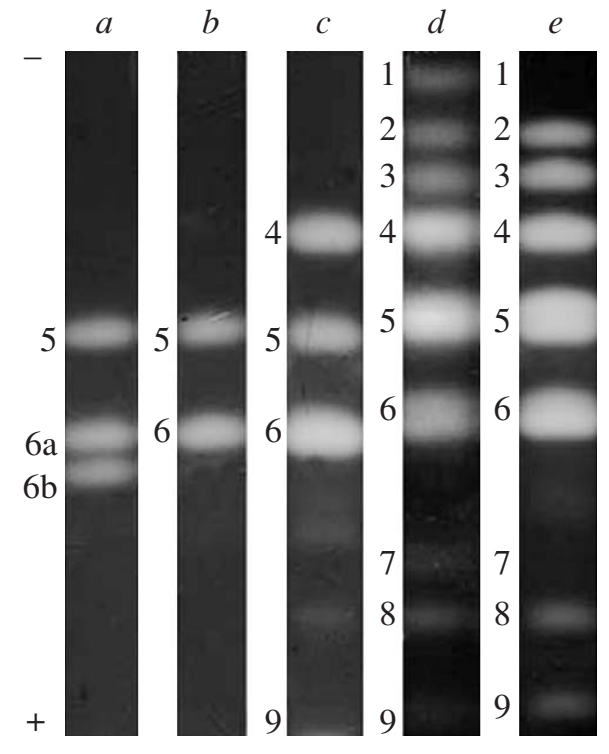

Fig. 2. The electrophoretic spectra of $\alpha$-amylase isozymes of some T. timopheevii and T. boeoticum genotypes: $a, b-$ $T$. boeoticum, $c-T$. timopheevii, $d$-Avrora; $e$-Mutiko italicum.

are located on the 6A, or when one of them is Amy3, which is located on the 5A chromosome. This might explain why the exploitation of nulli-tetrasomics for the $6^{\text {th }}$ group is ineffective in the localization of genes that control malt-zone bands. The spectrum of the einkorn lacks bands 3 and 8, which are encoded by Amy-Al and $A m y-A 2$ genes located on chromosomes $6 \mathrm{~A}$ and $7 \mathrm{~A}$ respectively of common ( $\left.\mathrm{A}^{\mathrm{u}} \mathrm{A}^{\mathrm{u}} \mathrm{BBDD}\right)$ and, possibly, durum wheat. So, the $\alpha$-amylase spectrum of einkorn wheat gives an insight into which bands are produced exceptionally by $\mathrm{A}^{\mathrm{b}}$ genome, which is present as a subgenome in the tetraploid T. timopheevii. It differs from the spectrum provided by $\mathrm{A}^{\mathrm{u}}$ subgenome, which we could observe on spectra of common and durum wheats.

The $\alpha$-amylase spectrum of $T$. timopheevii lacks bands 3 and 8 , which are present on spectra of common and durum wheat and point on the expression of genes located on chromosomes 6A and 7A. So, there is some accordance between the spectra of einkorn and Timopheevii wheat. The comparison of diploid and tetraploid wheat spectra leads to a conclusion that the upper component (4) on the invariable triplet and the lower band of the green-zone are controlled by chromosomes of $\mathrm{G}$ and $\mathrm{B}$ subgenomes of Timopheevii and durum wheats, respectively.

Wild einkorn, the boeoticum wheat, also lacks on its spectrum bands 3 and 7, which are controlled by chromosomes of common wheat $\mathrm{A}^{\mathrm{u}}$ subgenome. Therefore, we could presume that the initial gene of the einkorn wheat of the $\mathrm{A}^{\mathrm{b}}$ subgenome is duplicated in comparison to genome $\mathrm{A}^{\mathrm{b}}$, and these genes encode different bands. So, the comparison of spectra of diploid, two tetraploid

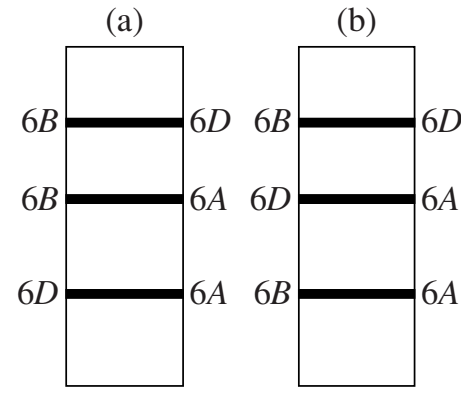

Fig. 3. Some variants of chromosomal control of the bands in invariable triplet of $\alpha$-amylase in common wheat.

and one hexaploid wheat provides evidence that the upper band of the triplet is encoded by G (B) subgenome, but leaves unclear how the next two bands are controlled. The other assumption occurs: if two bands of triplet, 5 and 6 , are controlled by one genome $\left(\mathrm{A}^{\mathrm{b}}\right.$ of T. boeoticum), it might be possible that $\mathrm{B}$ or $\mathrm{G}$ subgenomes, as well as D one of common wheat, may encode two isozymes each. If some isozymes have equal electrophoretic mobility, they should collide on the spectrum and as a result decrease the number of the bands on spectrum and form the invariable triplet. Moreover, that should cause ineffectiveness of nulli-tetrasomics exploitation in gene location definition. Figure $3 \mathrm{dem}-$ onstrates two most plain schemes of electrophoretic band genetic control in hexaploid wheat. It should be noted that neither of these schemes for common wheat, Figs. $3 a$ and $3 b$, is more trustworthy than the other due to the absence of the appropriate genetic stocks.

It must not be ruled out that one of the $\alpha$-amylase bands of the T. boeoticum is controlled by Amy-AI (6A), and the other is controlled by Amy-A3 (5A). Figure 4 demonstrates six most plain schemes of electrophoretic band genetic control in tetraploid wheat, which explain the presence of three components in the invariable spectrum part. Durum wheat genotypes, which were used in our investigation and showed the polymorphism in the invariable malt-zone triplet, offer an opportunity of shedding some light on the genetic control of the invariable triplet bands.

For the genetic analysis the combinations Leucurum $\times$ Rubrum, MI $\times$ Leucurum, and MI $\times$ Rubrum were used due to their difference in the $\alpha$-amylase malt-zone triplet on the electrophoretic spectra (Fig. 1). Four seeds from each $\mathrm{F}_{2}$ individual were randomly taken, and the extracted $\alpha$-amylase was separated electrophoretically. On the basis of the four seeds spectra the genotype for genes that control $\alpha$-amylase of each $\mathrm{F}_{2}$ individual was reconstructed. As cultivar Leucurum has no upper band on its spectrum, we can not distinguish a homozygote for its alternative allele, which demonstrates a band, from a heterozygote for this gene. So, there could be only two phenotypic classes: homozygotes for the nullallele (no band) and general class that consists of homoand heterozygotes, demonstrating the upper band. 


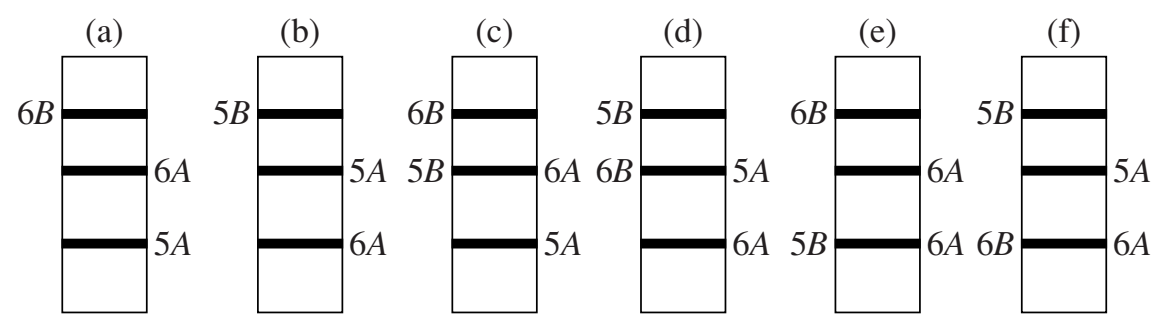

Fig. 4. Some variants of chromosomal control of bands in invariable triplet of $\alpha$-amylase in durum wheat.
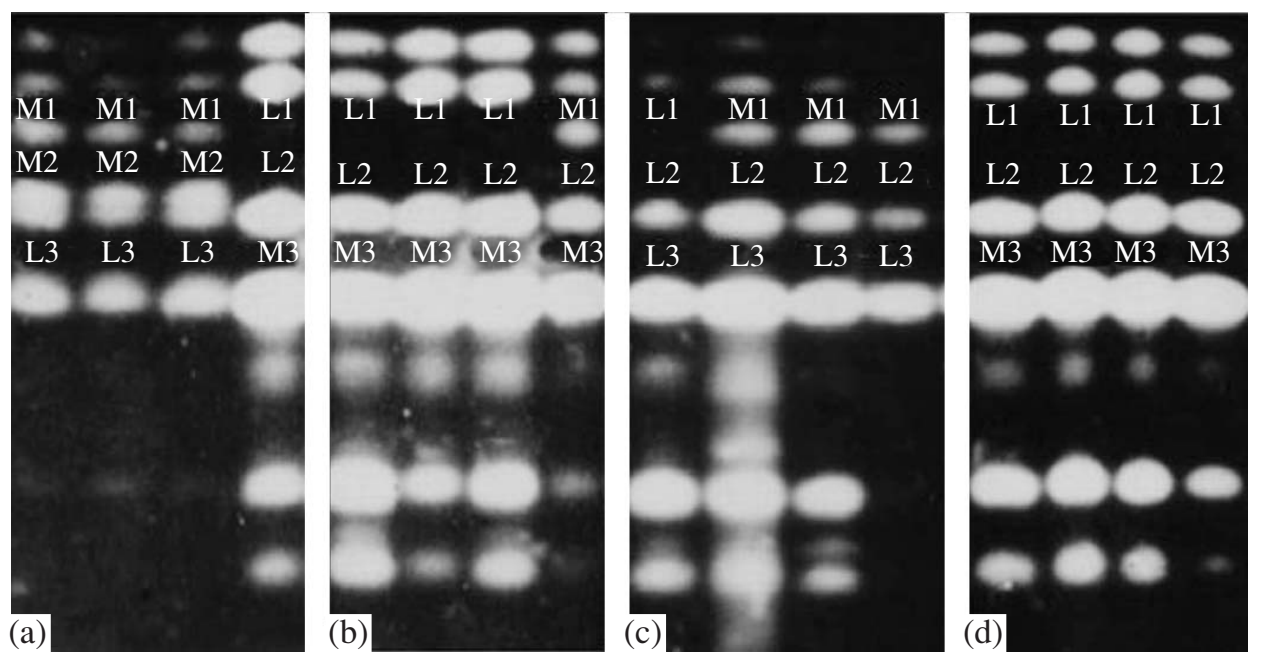

Fig. 5. Some examples of $\alpha$-amylase electrophoretic spectra of four $F_{3}$ seeds grown on the $F_{2}$ plant, crossing combination MI $\times$ Leucurum: (a) M1L1M2L2M3L3 genotype of the parent plant $F_{2}$; (b) M1L1L2L2M3M3; (c) M1L1L2L2L3L3; (d) L1L1L2L2M3M3.
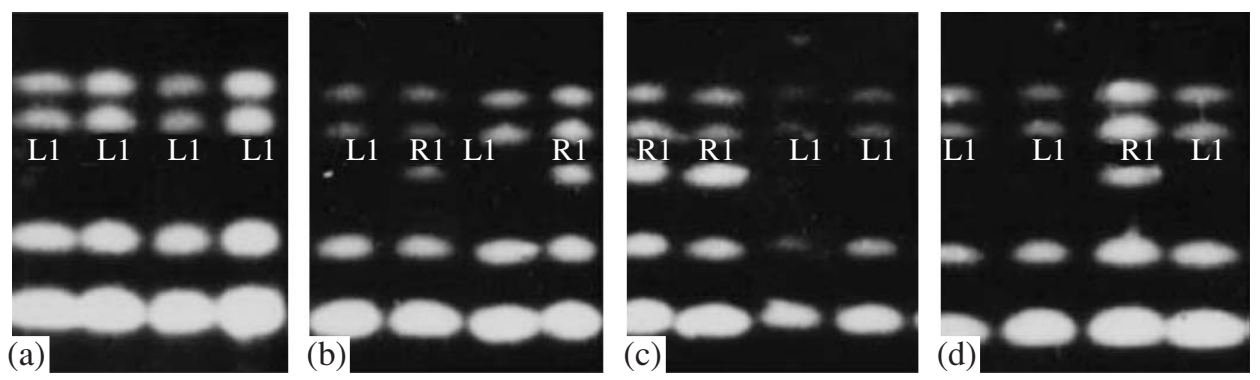

Fig. 6. Some examples of $\alpha$-amylase electrophoretic spectra of four $\mathrm{F}_{3}$ seeds grown on the $\mathrm{F}_{2}$ plant, crossing combination Leucurum $\times$ Rubrum: (a) L1L1 genotype of the parent plant $\mathrm{F}_{2}$; (b-d) L1R1.

The same concerns the second and the third bands of triplet. The double bands provided by MI genotype collide with the respective single bands of other genotypes; therefore, according to genes that control two lower triplet bands $\mathrm{F}_{2}$ plants could be divided into two phenotypic classes: homozygotes with the single band phenotype, and homo- and heterozygotes with the double bands phenotype.

From the $\alpha$-amylase electrophoretic spectra it could be drawn that the individuals from the cross combination Leucurum $(\mathrm{L}) \times \mathrm{MI}(\mathrm{M})$ differ in three genes. We expect $3: 1$ segregation for one gene (the band is present or it is absent); consequently, for three genes phenotypic ratios should match $(3: 1)^{3}$. In the cross combination Leucurum $\times$ Rubrum $(\mathrm{R})$, where parental forms differ in one gene, which encodes the upper triplet band, $3: 1$ segregarion is expected. MI and Rubrum differ in two genes controlling $\alpha$-amylase isozymes, therefore, in $\mathrm{F}_{2}(3: 1)^{2}$ ratio between phenotypic classes is expected. Figure 5 demonstrates electrophoretic spectra of $\mathrm{F}_{3}$ individuals obtained from the crossing different cultivars; bands are defined via letter (that means 
The distribution of $\mathrm{F}_{2}$ individuals into phenotypic classes after $\alpha$-amylase electrophoretic spectrum bands in the analyzed combinations

\begin{tabular}{|c|c|c|c|c|c|}
\hline \multirow{2}{*}{ Phenotypic classes } & \multicolumn{2}{|c|}{ Volumes } & \multirow{2}{*}{ Phenotypic classes } & \multicolumn{2}{|c|}{ Volumes } \\
\hline & of empiric classes & of theorelie classes & & of empiric classes & of theorelie classes \\
\hline \multicolumn{3}{|c|}{ Leucurum $\times$ MI } & \multicolumn{3}{|c|}{ Leucurum $\times$ Rubrum } \\
\hline $27 \mathrm{M} 1 \mathrm{M} 2 \mathrm{M} 3$ & 65 & 60.75 & $3 \mathrm{R} 1$ & 76 & 74.25 \\
\hline 9 M1M2L3 & 19 & 20.25 & $1 \mathrm{~L} 1$ & 23 & 24.25 \\
\hline 9 M1L2M3 & 18 & 20.25 & Total & 99 & \\
\hline 9 L1M2M3 & 17 & 20.25 & $\chi^{2}$ value & & $0.16<\chi^{2}$ st 0.01 \\
\hline 3 M1L2L3 & 8 & 6.75 & \multicolumn{3}{|c|}{ MI $\times$ Rubrum } \\
\hline 3 L1L2M3 & 2 & 6.75 & $9 \mathrm{M} 2 \mathrm{M} 3$ & 48 & 63 \\
\hline 3 L1M2L3 & 12 & 6.75 & $3 \mathrm{M} 2 \mathrm{R} 3$ & 21 & 21 \\
\hline $1 \mathrm{~L} 1 \mathrm{~L} 2 \mathrm{~L} 3$ & 3 & 2.25 & $3 \mathrm{R} 2 \mathrm{M} 3$ & 31 & 21 \\
\hline Total & 144 & & $1 \mathrm{R} 2 \mathrm{R} 3$ & 12 & 7 \\
\hline$\chi^{2}$ value & & $9.05<\chi^{2}$ st 0.01 & & 112 & $20.96<\chi^{2}$ st 0.01 \\
\hline
\end{tabular}

corresponding cultivar) and number (that means the position in the triplet zone). Bands M1 and R1, R2 and L2, R3 and L3 are not analyzed due to their identity. Bands M1 and R1 dominate over L1; consequently, M1M1 and M1L1, R1R1 and R1L1 are identical, too. In the same way, band M2 dominates over R2, and M3R3, and genotypes M2M2 and M2R2, M3M3 and M3R3 could not be distinguished.

The distribution of the $\mathrm{F}_{2}$ plants into phenotypic classes (table) agrees with the theoretically expected one in those two crossing combinations, where Leucurum was one of the parental forms. The empiric distribution differs from the theoretic one in the combination, in which $\mathrm{Ml}$ was one of the parental forms. A deficit of plants in classes with bands M2 and M3 is observed. MI has rather weak frost-resistance, so, it is fear to presume that among $\mathrm{F}_{2}$ individuals did not winter those ones figures that possessed, first of all, originated from MI 5A chromosome, which is known as a carrier of several genes that control frost resistance [17-19]. Under negative selection occurred genes located on the $5 \mathrm{~A}$ chromosome, among which was $A m y-A 3$ gene. Consequently, we could presume that the central band of the invariable malt-zone triplet is controlled exactly by this gene. So, schemes in Figs. 4d and $4 \mathrm{f}$ could be thought of ones as more realistic as for chromosomal control of the bands in the invariable part of $\alpha$-amylase spectrum of durum wheat.

\section{CONCLUSIONS}

The invariable malt-zone triplet of $\alpha$-amylase in tetraploid wheats with genome formulas $\mathrm{A}^{\mathrm{u}} \mathrm{A}^{\mathrm{u}} \mathrm{BB}$ and $\mathrm{A}^{\mathrm{b}} \mathrm{A}^{\mathrm{b}} \mathrm{GG}$ is controlled by three genes, which recombine independently. Two of them are controlled by the genes of the A subgenome: the lowest band is a product of the
Amy-A1, located on the 6A chromosome, the central triplet's band is a product of Amy-A3, located on 5A chromosome. The upper band is encoded by subgenomes B of T. durum and $\mathrm{G}$ of $T$. timopheevii.

\section{REFERENCES}

1. Huang, N., Stebbins, G.L., and Rodriguez, R.L., Classification and Evolution of Amylase Genes in Plant, Proc. Nat. Acad. Sci. USA, 1992, vol. 89, pp. 7526-7530.

2. Lazarus, C.M., Baulcombe, D.C., and Martienssen, R.A., $\alpha$-Amylase Genes of Wheat Are Two Multigene Families Which Are Differentially Expressed, Plant Mol. Biol., 1985, vol. 5, pp. 13-24.

3. Baulcomble, D.C., Huttly, A.K., Martienssen, R.A., Barker, R.F., and Jarvis, M.G., A Novel Wheat $\alpha$-Amylase Gene ( $\alpha$-Amy3), Mol. Gen. Genet., 1987, vol. 209, pp. 33-40.

4. Sargeant, J.G., Amylase Enzymes and Starch Degradation, Cereal Res. Communs., 1980, vol. 8, pp. 77-86.

5. Jacobsen, J.V. and Higgins, T.J.V., Characterization of the $\alpha$-Amylases Synthesized by Aleurone Layers of Himalaya Barley in Response to Gibberellic Acid, Plant Physiol., 1982, vol. 70, pp. 1647-1653.

6. Appleford, N.E.J. and Lenton, J.R., Hormonal Regulation of $\alpha$-Amylase Gene Expression in Germinating Wheat (Triticum aestivum) Grains, Physiol. Plant., 1997, vol. 100, pp. 534-542.

7. Nishikawa, K. and Nobuhara, M., Genetic Studies of $\alpha-$ Amylase Isozymes in Wheat. 1. Location of Genes and Variation in Tetra- and Hexaploid Wheat, Jap. J. Genet., 1971, vol. 46, pp. 345-353.

8. Nishikawa, K., Furuta, Y., Hina, Y., et al., Genetic Studies of $\alpha$-Amylase Isozymes in Wheat. 4. Genetic Analysis of Hexaploid Wheat, Japan J. Genet., 1981, vol. 56, pp. 385-393. 
9. Gale, M.D., Law, C.N., Chojecki, A.J., et al., Genetic Control of $\alpha$-Amylase Production in Wheat, Theor. and Appl. Genet., 1983, vol. 64, pp. 309-316.

10. Aisworth, C.C., Doherty, P., Edwards, K.G.K., et al., Allelic Variation at $\alpha$-Amylase Locus in Hexaploid Wheat, Theor. Appl. Genet., 1985, vol. 70, pp. 400-406.

11. Laurie, S., McKibbin, R.S., and Halford, N.G., Antisense SNF1-Related (SnRK1) Protein Kinase Gene Represses Transient Activity of an $\alpha$-Amylase $(\alpha-A m y 2)$ Gene Promoter in Cultured Wheat Embryos, J. Exp. Bot., 2003, vol. 54, no. 383, pp. 739-747.

12. http://beta.uniprot.org/uniprot/P08117. Reviewed, UniProtKB/Swiss-Prot P08117 (AMY3_WHEAT). Last modified February 26, 2008.

13. McIntosh, R.A., Hart, G.E., Devos, K.M., Gale, M.D., and Rogers, W.J., Catalogue of Gene Symbols for Wheat, in Proc. 9th Int. Wheat Genet. Symp., Saskatoon, 1998, vol. 5, p. 235.

14. Masoja, P. and Milczarski, P., Mapping QTLs for $\alpha-$ Amylase Activity in Rye Grain, J. Appl. Genet., 2005, vol. 46, no. 2, pp. 115-123.

15. Nevo, E., Nishikawa, K., Furuta, Y., et al., Genetic Polymorphisms of $\alpha$ - and $\beta$-Amylase Isozymes in Wild Emmer Wheat, Triticum diccocoides, in Israel, Theor. Appl. Genet., 1993, vol. 85, no. 8, pp. 1029-1042.
16. Belay, G. and Furuta, Yo., Zymogram Patterns of $\alpha$ Amylase Isozymes in Ethiopian Tetraploid Wheat Landraces: Insight into Their Evolutionary History and Evidence for Gene Flow, Genet. Res. Crop Evol., 2001, vol. 48, no. 5, pp. 507-510.

17. Rybalka, A.I., Bodelan, O.P., and Linvinenko, N.A., Genetic Analysis of $\alpha$-Amylase of Wheat Kernel, Genetika (Moscow), 1989, vol. 25, no. 12, pp. 2187-2198.

18. Antonyuk, M.Z. and Ternovskaya, T.K., Isozymes of Beta- and $\alpha$-Amylase for Identification of Genetic Material of Three Aegilops Species Involved in the Common Wheat Genome, Tsitol. Genet., 1995, vol. 29, no. 2, pp. 3-8.

19. Sutka, J. and Shape, J.W., Location of a Gene for Frost Resistance on Chromosome 5A of Wheat, Euphytica, 1989, vol. 42, no. 1/2, pp. 41-44.

20. Vagujfalvi, A., Aprile, A., Miller, A., et al., The Expression of Several $C b f$ Genes at the Fr-A2 Locus Is Linked to Frost Resistance in Wheat, Mol. Genet. Genom., 2005, vol. 274, no. 5, pp. 506-514.

21. Miller, A.K., Galiba, G., and Dubcovsky, J., A Cluster of $11 \mathrm{CBF}$ Transcription Factors Is Located at the Frost Tolerance Locus Fr-Am2 in Triticum monococcum, Mol. Genet. Genom., 2006, vol. 275, no. 2, pp. 193-203. 